3 McKee M. Indicators of clinical performance. BMJ 1997;315:142

Butler R. Discussion. In: Goldstein H, Spiegelhalter D. League tables and their limitations: statistical issues in comparisons of institutional performance. J R Statis Soc (A) 1996;159:409.

5 Wise J. Clinical indicators for hospitals announced. BMJ 1997;315:76.

6 Tarnow-Mordi WO, Ogston AR, Wilkinson AR, Reid E, Gregory J, Saeed $\mathrm{M}$, et al. Predicting death from initial disease severity in very low birthweight infants: a method for comparing the performance of neonatal units. BMJ 1990;300:1611-4

7 The International Neonatal Network. The CRIB (clinical risk index for babies) score: a tool for assessing initial neonatal risk and comparing performance of neonatal intensive care hospitals. Lancet 1993;342:192-8.

8 De Courcy Wheeler RHB, Wolfe CDA, Fitzgerald A, Spencer M, Goodman JD, et al. Use of the CRIB (clinical risk index for babies) score in prediction of neonatal mortality and morbidity. Arch Dis Child 1995;73:F32-36

9 Hanley JA, McNeil BJ. A method of comparing the areas under the receiver operating characteristic curves derived from the same cases Radiology 1983;148:839-43.

10 Hosmer DW, Lemeshow S. Applied logistic regression. New York: Wiley, 1989.

11 Yates DW, Woodford M, Hollis S. Preliminary analysis of the care of injured patients in 33 British hospitals: first report of the United Kingdom major trauma outcome study. BMJ 1992;305:737-40.

12 Armitage P, Berry G. Statistical methods in medical research. 3rd ed. London: Blackwell Scientific, 1994.

13 Rockall TA, Logan RFA, Devlin HB, Northfield TC, for the national audit of acute upper gastrointestinal haemorrhage. Selection of patients for early discharge or outpatient care after acute upper gastrointestinal haemorrhage. Lancet 1995;346:346-50.

14 Green J, Wintfeld N. Report cards on cardiac surgeons: assessing New York state's approach. N Engl J Med 1995;332:1229-32.

15 Goldstein H, Spiegelhalter DJ. League tables and their limitations: statistical issues in comparisons of institutional performance. J R Statist Soc (A) 1996;159:385-443.
16 Tarnow-Mordi WO, Parry GJ, Gould C, Fowlie PW. CRIB and performance indicators for neonatal intensive care units (NICUs) [letter] Arch Dis Child 1996;74:F79-80

17 Mant J, Hicks N. Detecting differences in quality of care: the sensitivity of measures of process and outcome in treating acute myocardial infarction. BMJ 1995;311:793-6.

18 Scottish Neonatal Consultants Collaborative Study Group and International Neonatal Network. Trends and variations in use of antenatal corticosteroids to prevent neonatal respiratory distress syndrome: recommendations for national and international comparative audit. BrJ Obstet Gynaecol 1996;103:534-40.

19 Pearson G, Shann F, Barry P, Vyas J, Thomas D, Powell C, et al. Should paediatric intensive care be centralised? Trent versus Victoria. Lancet 1997;349:1213-7.

20 Kendrick S. Discussion. In: Goldstein H, Spiegelhalter D. League tables and their limitations: statistical issues in comparisons of institutional performance. J R Statist Soc (A) 1996;159:433.

21 Pollack MM, Cuerdon T, Patel KM, Ruttimann UE, Getson PR, Levetown M. Impact of quality of care factors on pediatric intensive care unit mortality. JAMA 1994;272:941-6.

22 Tarnow-Mordi WO, Tucker JS, McCabe CJ, Nicolson P, Parry GJ for the UK Neonatal Staffing Study Collaboration Group. The UK neonatal staffing study: a prospective evaluation of neonatal intensive care in the United Kingdom. Semin Neonatology 1997;2:171-9.

23 Tarnow-Mordi W, Parry G. Inappropriate and appropriate comparison of intensive care units using the clinical risk index for babies and pediatric risk of mortality scores. In: Goldstein H, Spiegelhalter D. League tables and their limitations: statistical issues in comparisons of institutional performance. JR Statist Soc (A) 1996;159:436.

24 The UK Neonatal Staffing Study. http://www.child-health.dundee.ac.uk/ research/UKneonatal-staffing/.

25 Fowlie PW, Gould CR, Tarnow-Mordi WO, Parry GJ, Phillips G. CRIB (clinical risk index for babies) in relation to nosocomial bacteraemia in very low birthweight or preterm infants. Arch Dis Child 1996;75:F49-52. (Accepted 12 February 1998)

\title{
Effect of flutamide on survival in patients with pancreatic cancer: results of a prospective, randomised, double blind, placebo controlled trial
}

\author{
Brian A Greenway
}

\begin{abstract}
Objectives: To assess whether flutamide (Drogenil), a pure androgen receptor blocking agent, improves survival in patients with pancreatic carcinoma and thus whether testosterone is a major growth factor for this tumour.

Design: A prospective, randomised, double blind placebo controlled trial.

Subjects: 49 patients with a clinical diagnosis of pancreatic carcinoma.

Interventions: 24 patients received flutamide and 25 received placebo.

Main outcome measures: Death of the patient.

Results: Analysis of all patients at 6 months and 1 year showed 14 and eight patients alive, respectively, in the flutamide group compared with 10 and one in the placebo group. After exclusion of those patients in both groups who received less than 6 weeks' treatment because of advanced disease and early death the comparable results were $14(88 \%)$ and eight $(50 \%)$ alive in the flutamide group compared with $10(50 \%)$ and one (5\%) in the placebo group. Median survival for all patients was 8 months in the flutamide group compared with 4 months in the placebo group. With the 6 week exclusions median survival was 12 months compared with 5 months, respectively.
\end{abstract}

Conclusions: This study supports the concept that testosterone is a growth factor for pancreatic carcinoma and that blockade of androgen receptors offers an appropriate new approach to treatment.

\section{Introduction}

Pancreatic cancer is difficult to diagnose and unsatisfactory to treat, with most patients dying within 6 months of diagnosis and virtually all by 1 year. ${ }^{12}$ At present surgery offers the only prospect of longer survival.

Testosterone may have a positive effect on the growth of pancreatic carcinoma. This would be supported if specific androgen receptor blockade improved survival. The concept is supported by the presence of androgen receptors within human pancreatic cancer tissue, ${ }^{3}$ together with the enzymes, aromatase and $5 \alpha$-reductase, which convert testosterone into either oestradiol or a more active androgen, $5 \alpha$-dihydrotestosterone, respectively. ${ }^{4}$ Furthermore, all patients with pancreatic cancer have low serum testosterone concentrations. ${ }^{56}$

Confirmatory evidence for this central role of testosterone came with the demonstration of its growth potentiating action on human pancreatic adencocarcinoma xenografts grown in nude mice, together with the inhibiting action of an antiandrogen.?

\section{Patients and methods}

The trial was conducted at Hinchingbrooke Hospital, Huntingdon, between October 1993 and January 1997

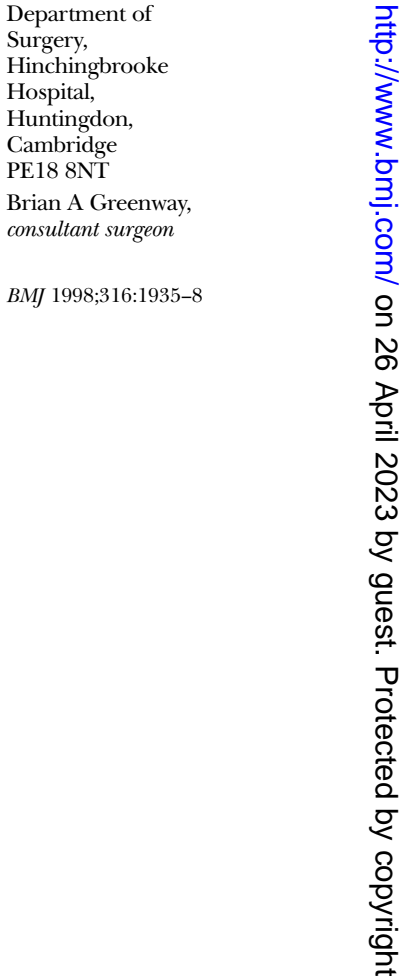


and was approved by the appropriate ethical committee. This is a district general hospital serving a population of about 170000 . Normally, such a hospital would see about 15 patients a year with pancreatic cancer. This hospital, however, is a referral unit for endoscopic retrograde cholangiopancreatography (ERCP) for a wide area of East Anglia, Hertfordshire, and Bedfordshire, which enabled the inclusion of 49 patients in the study over a 3 year period. All patients informed about the trial and who met the inclusion criteria readily accepted the opportunity to participate. Only one patient stopped treatment during the conduct of the trial because he wanted to know to which treatment he had been allocated; he is still included in the analyses because of intention to treat. The pancreatobiliary unit is relatively new, and normally I would perform a pancreatoduodenectomy for either carcinoma of the pancreas or ampulla of Vater at a rate of about one every 2 months. The criterion for resection for carcinoma of the pancreas was that the tumour was about $1 \mathrm{~cm}$ in size, on the basis of computed tomography, with no signs of spread at laparotomy.

Forty nine consecutive patients (26 men, 23 women; median age 68 (range 47-85) years) with a clinical diagnosis of pancreatic carcinoma, whatever the tumour load, who satisfied the inclusion criteria were entered into the study. They were numbered from 1 to 49 after independent randomisation. Before the initiation of the study a random code was generated by an independent company (Til Occam). This code was used to assign treatment on the basis of the order of patients admitted to the trial; study medications were blinded to both investigator and patient through the use of placebo. As the trial progressed, however, some men in the flutamide treatment group became aware of their treatment group because of side effectsnamely, breast tingling and gynaecomastia; this had been discussed with all patients at the start of the trial.

\section{Diagnosis and treatment}

The diagnosis of cancer was based on the typical but non-specific history of jaundice, weight loss, and upper abdominal or back pain, or both, in the absence of a significant intake of alcohol with two or more of the following findings at investigation: isolated pancreatic mass demonstrated on enhanced computed tomography; typical low bile duct stricture at endoscopic retrograde cholangiopancreatography (40 patients), usually with an isolated pancreatic duct stricture, the double duct sign; and histological confirmation by open biopsy or analysis of ascitic fluid (17 patients). Patients with macroscopic tumour at the ampulla of Vater or duodenum, which could be mistaken for primary tumours of these structures, were excluded from the study. Forty patients had a tumour within the head of the gland and nine in the body (table 1).

Most patients had been referred from within the East Anglian region for endoscopic retrograde cholangiopancreatography, and 32 had a biliary stent under the care of Dr Richard Dickinson. Patients fulfilling the diagnostic criteria gave informed signed consent and their referring physician and general practitioner were contacted regarding entry into the trial. Their weight was documented, and the trial tablets, which were both similar, were obtained from the hospital pharmacy in numbered vials in monthly amounts; the flutamide dosage was $250 \mathrm{mg}$ three times daily. All patients were seen and weighed each month in outpatient departments or before if there was a clinical problem. Complications of pancreatic cancer were specifically looked for, especially blockage of the biliary stent, pain control, enzyme insufficiency, diabetes, and duodenal obstruction. Every 3 months a further enhanced computed tomogram was obtained. Before entry into the study seven patients had had a double bypass operation, three had a gastrojejunostomy during treatment, and one a biliary bypass. The end point of the study was the death of the patient from whatever cause.

The stage of the tumour of patients in the trial could not be accurately assessed in all cases because a laparotomy is usually necessary in those without obvious distant metastases. So called early pancreatic cancer (pT1, UICC Classification of Pancreatic Tumours pTNM, 4th edition, 1987) with no extension beyond the pancreas is probably rare, however, as most patients will have extension to the neurolymphatic plexuses around the coeliac axis at diagnosis. Seventeen patients had isolated tumours on computed tomography of $2-3 \mathrm{~cm}$ in size (pT1b), the 32 remaining patients had tumours larger than $4 \mathrm{~cm}$, which included 17 who had liver metastases or ascites, or both, at presentation.

\section{Power and analysis}

The study was designed to test the null hypothesis that there would be no difference in survival time according to treatment against an alternate hypothesis of longer survival with flutamide treatment. This trial had $90 \%$ power to detect a difference if the 1 year survival rate with flutamide is between $40 \%$ and $50 \%$ (with 25 in each group, keeping the risk of a false positive at $5 \%$, and knowing that the 1 year survival for patients with cancer of the pancreas is $<10 \%$ at present). Any increases in survival would improve the power of the trial to determine a difference. A previous pilot study with six patients showed a 1 year survival of $100 \%$; none of those patients were included in this study.

Statistical analysis was performed with SAS. Significance tests were two tailed and carried out at the $5 \%$ level. To assess whether there was a treatment difference relating to tumour size according to computed tomography, changes in size of tumours from baseline to 3 months were analysed by unpaired $t$ test.

\section{Results}

An intention to treat analysis was carried out which included all 49 patients recruited to the study. A per protocol analysis was also carried out for the 36 patients who received more than 6 weeks of study treatment. This

Table 1 Baseline characteristics of patients with pancreatic cancer according to treatment group

\begin{tabular}{lcc} 
Detail & $\begin{array}{c}\text { Flutamide } \\
(\mathbf{n = 2 4 )}\end{array}$ & $\begin{array}{c}\text { Placebo } \\
(\mathbf{n}=\mathbf{2 5})\end{array}$ \\
\hline No of men & 13 & 13 \\
\hline Median (range) age (years) & $67.8(50-85)$ & $68.6(47-84)$ \\
\hline Position of tumour in gland: & & \\
\hline Head & 18 & 22 \\
\hline Body & 6 & 3 \\
\hline Liver metastases or ascites, or both, at presentation & 11 & 6 \\
\hline Histological confirmation & 12 & 5 \\
\hline
\end{tabular}


Table 2 Survival time of all patients with pancreatic cancer according to treatment group

\begin{tabular}{lcc} 
Detail & $\begin{array}{c}\text { Flutamide } \\
(\mathbf{n}=\mathbf{2 4})\end{array}$ & $\begin{array}{c}\text { Placebo } \\
(\mathbf{n}=\mathbf{2 5})\end{array}$ \\
\hline No $(\%)$ alive & $2(8)$ & 0 \\
\hline No $(\%)$ dead & $22(92)$ & $25(100)$ \\
\hline Estimated time* by which $50 \%$ of patients were & 226 & 120
\end{tabular}

. dead (days) $\dagger$

*By Kaplan-Meier.

tP value for treatment comparison 0.079 by generalised Wilcoxon test and 0.011 by log rank test.

Table 3 Survival time of all patients with pancreatic cancer who received more than 6 weeks' treatment according to treatment group

\begin{tabular}{lcc} 
Detail & $\begin{array}{c}\text { Flutamide } \\
(\mathbf{n = 1 6 )}\end{array}$ & $\begin{array}{c}\text { Placebo } \\
(\mathbf{n = 2 0})\end{array}$ \\
\hline No $(\%)$ alive & $2(12)$ & 0 \\
\hline No $(\%)$ dead & $14(88)$ & $20(100)$ \\
\hline Estimated time* by which $50 \%$ of patients were & 350.5 & 165.5
\end{tabular}
dead (days) $\dagger$

\section{*By Kaplan-Meier.}

$\dagger \mathrm{P}$ value for treatment comparison 0.001 by generalised Wilcoxon test and 0.001 by log rank test.

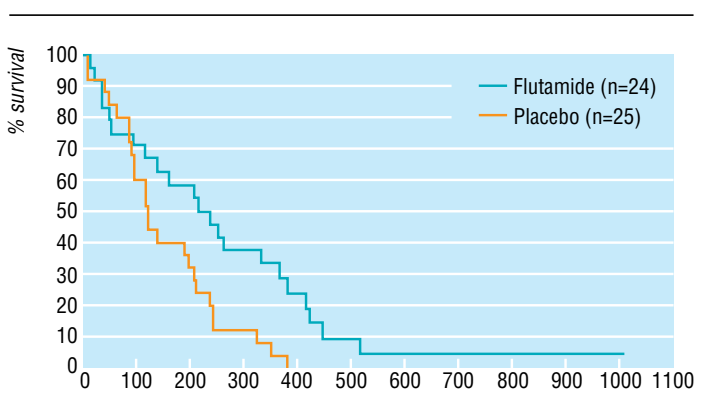

Fig 1 Survival time of all patients with pancreatic cancer according to treatment group

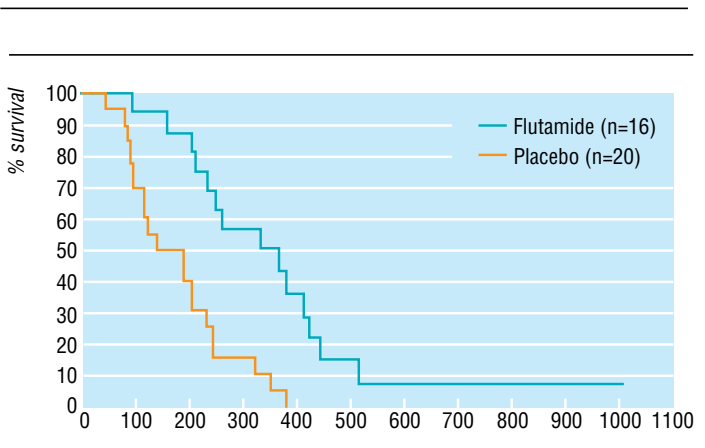

Fig 2 Survival time of patients with pancreatic cancer who received over 6 weeks' treatment according to treatment group

cut off period, which applied to all patients, was chosen to exclude those 13 (eight in the flutamide group, five in the placebo group) with a heavy tumour load, including liver metastases and ascites, who died within this period and who would probably not have taken sufficient medication for an effect.

The survival times were calculated and missing data were analysed as censored at the time of the latest available follow up data. Kaplan-Meier estimates of the times at which half patients remained alive were calculated. Treatments were compared by the log rank and generalised Wilcoxon tests.
Survival time for all patients was analysed first, and at final analysis two patients were still alive in the flutamide group (8\%) and none in the placebo arm (table $2)$. The median survival for the treatment group was 226 days (8/12) compared with 120 days (4/12) for the placebo arm (fig 1). Comparison of treatment by the generalised Wilcoxon test gave $\mathrm{P}=0.079$ and by the $\log$ rank test $\mathrm{P}=0.01$. The slight difference between the results from the two tests was because the log rank test gives greater emphasis to treatment differences that occur at later time points, which is where the most pronounced differences are seen in these data.

For those patients receiving more than 6 weeks' treatment the median survival times were 350.5 days $(12 / 12)$ for those treated with flutamide versus 165.5 days $(5 / 12)$ for those receiving placebo (fig 2). Again, treatment comparisons by generalised Wilcoxon test gave a value of $\mathrm{P}=0.001$, while the $\log$ rank test gave $\mathrm{P}=0.001$ (table 3).

Statistical analysis of changes in tumour size on the basis of computed tomography did not show a significant difference between the groups when they were assessed from 0 to 3 months. Later analysis was more difficult as several patients had died, reducing numbers for comparison. There was no significant difference in survival between men and women in the treatment group.

At final analysis the side effects of treatment experienced by the patients on flutamide could be grouped into three. Firstly, there was the effect on the male breast, which was mild tingling in 55\%, with overt gynaecomastia in three patients. Secondly, there was gastrointestinal disturbance-namely, diarrhoea-which was self limiting and did not necessitate stopping treatment in the eight patients affected. Thirdly, one patient developed paraesthesia-namely, a tingling sensation in all limbs which stopped on cessation of treatment.

\section{Discussion}

This study has shown a doubling of survival for patients taking flutamide and provides support for the central role of testosterone as a growth factor in pancreatic cancer.

In a previous study with the antiandrogen cyproterone acetate no clinical effect was shown. ${ }^{8}$ This may be because it has inherent androgenic activity. ${ }^{9}$ Animal and human studies with analogues of luteinising hormone releasing hormone, which reduce serum testosterone concentrations, however, have shown promising effects in inhibiting tumour growth. ${ }^{1011}$ After the demonstration of oestrogen receptors within pancreatic cancer tissue ${ }^{12}$ several studies were performed with tamoxifen, but none showed a consistent positive effect. ${ }^{13}{ }^{14}$ In this study the sex difference was hardly noticeable at 1.1:1 (men:women). Normally this is somewhere about 1.25-1.4:1. This probably reflects the wide referral nature of the patients.

There was no significant difference with regard to changes in tumour size assessed at baseline and at 3 months on computed tomography, the main problem being the reduction in patient numbers as time progressed. It was notable on the scans of several patients treated with flutamide, however, especially in those who survived longest, that the size of the tumours did not change until a terminal stage was reached, when 
Key messages

- Previous work suggests that androgens may be involved in the growth of pancreatic cancer

- This study shows that the antiandrogen flutamide doubles median survival in patients with pancreatic cancer

- The treatment is well tolerated by patients with minimal side effects, an important consideration in those with advanced malignant disease

- The concept that testosterone may be a growth factor in pancreatic adenocarcinoma is supported by this trial

the tumour would rapidly expand. I have interpreted this as the tumour possibly escaping from androgen blockade; this effect is seen with prostatic carcinoma. ${ }^{15}$

There were no consistent findings with regard to weight changes or performance status, many patients gaining weight terminally when ascites appeared. The Karnofsky index was used but the main problem is its objective bias. At the start of treatment $80 \%$ of patients were considered as between able to carry on normal activities and self caring but unable to do active work (Karnofsky scale 90-70). A fifth required considerable assistance and frequent medical care (Karnofsky scale 50-40). No patient was initially considered as terminal, even though 13 patients deteriorated and died within 6 weeks. All were enthusiastic about participating in the trial. Protocols of measurements of quality of life were not available at the start of this trial.

\section{Reliability of diagnosis}

Although histological confirmation of diagnosis was obtained in 17 patients, computed tomography ${ }^{16}$ and endoscopic retrograde cholangiopancreatography ${ }^{17}$ each give a diagnostic accuracy in excess of $90 \%$, the latter also excluding carcinomas of the ampulla of Vater and periampullary region. The differential diagnosis of pancreatic carcinoma may include cholangiocarcinomas of the lower third of the common bile duct, but this is a distinction that can often be made only on careful dissection of resection specimens. Secondary carcinomas and lymphomas are extremely uncommon, and other solid (that is, non-cystic) pancreatic malignancies account for less than 3-5\% of unselected series. Fine needle aspiration biopsy sampling, which we introduced to the unit after the start of this study, may provide a less traumatic and relatively accurate option for diagnostic confirmation, notwithstanding a false negative rate and difficulty in classification of tumours of this region.

The typical natural history of pancreatic carcinoma seen in the survival graph for the control group (fig 1) is inconsistent with a benign diagnosis such as localised chronic pancreatitis; further support is provided by the exclusion of alcoholic patients from the trial, together with the absence of calcification on computed tomography. ${ }^{18}$ It is noteworthy that of the 12 patients in the flutamide group who had histological confirmation of adenocarcinoma, three were the longest survivors in the trial, six had large tumour loads with a short survival, and the three remaining patients survived between 3 and 8 months. Overall the strategy used in this trial would have ensured that at least $95 \%$ of patients had adenocarcinoma of the pancreas (Profes- sor Gordon Stamp, department of histopathology, Hammersmith Hospital, personal communication).

This study showed that flutamide was well tolerated and accepted by all patients, including those with advanced disease, with essentially minimal side effects. This is an extremely important consideration in the treatment of many seriously ill and debilitated patients with a limited life expectancy. It also suggests that flutamide seems to be an effective treatment for a disease with a poor prognosis. Further studies are now underway to try to improve on these results with additional therapies.

I thank Dr Barbara Latham, consultant anaesthetist, for her help with pain control for these patients; the consultant radiologists at Hinchingbrooke Hospital for performing and analysing results of computed tomography; and the many consultants who kindly referred patients and allowed their inclusion in this study. Also Professor Gordon Stamp, histopathologist, for very helpful discussions on the differential diagnosis of pancreatic carcinoma and Mr Christopher Russell, consultant surgeon, Middlesex Hospital, for reading the final manuscript.

Contributors: Dr Richard Dickinson, consultant physician, Hinchingbrooke Hospital, Huntingdon, referred most patients, carried out endoscopic retrograde cholangiopancreatography to assist in the diagnosis and differential diagnosis of pancreatic carcinoma, and read and reread the manuscript. His enthusiastic support has been central to this trial. Mr Peter Wilkinson, Matrix Contract Research, Naphill, Bucks, independently performed the trial analysis and statistics. BAG is the guarantor for the integrity of the entire project.

Funding: Schering-Plough pharmaceuticals. Initial randomisation was performed by Til Occam Ltd.

Conflict of interest: None.

1 Greenway BA. Carcinoma of the exocrine pancreas: a sex hormone responsive tumour. BrJ Surg 1987;74:441-2.

2 Rosewicz S, Wiedenmann B. Pancreatic carcinoma. Lancet 1997;349:485-9.

3 Corbishley TP, Iqbal MJ, Wilkinson ML, Williams R. Androgen receptor in human normal and malignant pancreatic tissue and cell lines. Cancer $1986 ; 57: 1992-5$

4 Iqbal MJ, Greenway BA, Wilkinson ML, Johnson PJ, Williams R. Sex steroid enzymes, aromatase and $5 \alpha$ reductase in the pancreas: a comparison of normal adult, foetal and malignant tissue. Clin Sci 1983;65:71-5.

5 Greenway BA, Iqbal MJ, Johnson PJ, Williams R. Low serum testosterone concentrations in patients with carcinoma of the pancreas. BMJ 1983;286:93-5.

6 Shearer MG, Taggart D, Gray C, Imrie CW. Useful differentiation between pancreatic cancer and chronic pancreatitis by testosterone assay. European Pancreatic Club XVI Meeting, Cascais, September 1984. Digestion 1984;A78.

7 Greenway BA, Duke D, Pym B, Iqbal MJ, Johnson PJ, Williams R. The control of human pancreatic adenocarcinoma xenografts in nude mice by hormone therapy. BrJ Surg 1982;69:595-7.

8 Keating JJ, Johnson PJ, Cochrane AM, Gazzard BG, Krasner N, Smith PM, et al. Prospective randomised controlled trial of Tamoxifen and cyproterone acetate in pancreatic carcinoma. Br J Cancer 1989;60:789-92.

9 Poyet P, Labrie F. Comparison of the antiandrogenic/androgenic activities of flutamide, cyproterone acetate and megestrol acetate. Mol Cell Endocrinology 1985;42:283-8

10 Redding TW, Schally AV. Inhibition of growth of pancreatic carcinomas in animal models by hypothalamic hormones. Proc Natl Acad Sci U S A 1984;81:248-52.

11 Gonzalez-Barcena D, Ibarra-Olmos MA, Garcia-Carrasco F, GutierrezSamperio M, Comaru-Schally AM, Schally AV. Influence of D-Trp-6LH-RH on the survival time in patients with advanced pancreatic cancer. LH-RH on the survival time in patie
Biomed Pharmacother 1989;43:313-7.

12 Greenway BA, Iqbal MJ, Johnson PJ, Williams R. Oestrogen receptor proteins in malignant and foetal pancreas. BMJ 1981;283:751-3.

13 Tonnensen K, Kemp-Jensen M. Antioestrogen therapy in pancreatic carcinoma: a preliminary report. Eur J Surg Oncol 1986;12:69-70.

14 Taylor OM, Benson EA, McMahon MJ. Clinical trial of tamoxifen on patients with irresectable pancreatic adenocarcinoma. $\mathrm{Br} J$ Surg 1993;80:1083.

15 Isaacs JT, Coffey DS. Adaptation versus selection as the mechanism responsible for the relapse of prostatic cancer to androgen ablation therapy as studied in the Dunning R-3327-H adenocarcinoma. Cancer Res 1981;41:5070-5.

16 Freeny PC. Radiologic diagnosis and staging of pancreatic ductal adenocarcinoma. Radiol Clin North Am 1989;27:121-8.

17 Kaufman A, Swak M, Ferguson D. Endoscopic retrograde cholangiopancreatography in pancreatic islet cell tumours. Gastrointest Endosc 1988;34:47-52.

18 Freeny PC, Lawson TL. Radiology of the pancreas. New York: Springer Verlag, 1982.

(Accepted 23 February 1998) 